\title{
ANALISIS INVESTASI PENAMBAHAN AKTIVA TETAP (MESIN OVEN) PADA UD. WARNA SARI DI DESA SURANADI KECAMATAN NARMADA KABUPATEN LOMBOK BARAT
}

\section{GUSTI AGUNG DIDIT EKA PERMADI}

\author{
Program Studi Agribisnis Kampus Mataram UNMAS Denpasar \\ e-mail : diditekapermadi@gmail.com
}

\begin{abstract}
ABSTRAK
Tujuan penelitian ini adalah untuk menganalisis layak atau tidaknya rencana investasi penambahan aktiva tetap (mesin oven) oleh UD. Warna Sari, ditinjau dari aspek keuangan. Penelitian ini merupakan penelitian terapan (applied research), dengan metode pengumpulan data yaitu metode kasus, teknik pengumpulan data : observasi, wawancara dan dokumentasi. Alat pengumpulan data yang digunakan dalam penelitian ini adalah kuesioner dan tape recorder. Analisis data menggunakan analisis Net Present Value (NPV), Internal Rate of Return (IRR), Payback Period (PP), dan Profitability Index (PI).

Dari hasil penelitian ini dapat disimpulkan sebagai berikut : rencana investasi penambahan aktiva tetap (mesin oven) tersebut layak dilaksanakan oleh UD. Warna Sari, bila ditinjau dari aspek keuangan. Hal ini dapat dlihat dari Payback Period $(P P)=0,09$ tahun $<1$ tahun, Net Present Value $(N P V)$ sebesar Rp 473.330.270 bernilai positif, IRR (105,04\%)> RRR $(50 \%)$, PI $(60,17)>1$

Bagi pimpinan UD. Warna Sari, keputusan investasi penambahan aktiva tetap (mesin oven) ini layak untuk dilaksanakan untuk meningkatkan kapasitas produksi dodol nangka yang nilai penjualanya terus mengalami peningkatan dari tahun ke tahun.
\end{abstract}

Kata Kunci : Aktiva tetap,net present value, internal rate of return, payback period, profitability index.

\section{ABSTRACT}

The purpose of this study was to analyze the feasibility of an investment plan to add fixed assets (oven machines) by UD. Warna Sari in terms of financial aspects. This research is applied with data collection methods namely; case methods, data collection techniques: observation, interviews, and documentation. Data collection tools used in this study are questionnaire and tape recorder. Data analysis uses Net Present Value (NPV) analysis, Internal Rate of Return (IRR), Payback Period (PP), and Profitability Index (PI).

From the results of this study can be concluded as follows: investment plans to add fixed assets (oven machines) are feasible to be implemented by UD. Warna Sari, when viewed from the financial aspect. This can be seen from the Payback Period $(P P)=0.09$ years $<1$ year, Net Present Value (NPV) of Rp 473,330,270 is positive, IRR (105.04\%)> RRR (50\%), PI (60\%), 17)> 1

The investment decision to add fixed assets (oven machines) for business leader at UD. Warna Sari is feasible to be implemented to increase the production capacity of jackfruit dodol whose sales value continues to increase from year to year.

Keywords: fixed assets, net present value, internal rate of return, payback period, profitability index

\section{PENDAHULUAN}

\section{Latar Belakang}

Seiring dengan perkembangan zaman yang semakin pesat di tengah himpitan ekonomi yang semakin sulit mendorong sebagian masyarakat untuk terjun dalam dunia wirausaha yang dianggap lebih menjamin. Hal ini dapat dilihat dari semakin bertambahnya jumlah perusahaan yang ada, baik dalam skala besar, sedang maupun kecil. Pemerintah juga berupaya membantu masyarakat terutama masyarakat yang berekonomi 
menengah ke bawah dengan menggalakkan kembali program Usaha Kecil Menengah dan Koperasi (UKMK). Namun, keberhasilan suatu usaha tidak dapat dilihat hanya dari ukuran besar atau kecilnya usaha serta milik pemerintah maupun swasta, melainkan bagaimana perusahaan tersebut dapat menjalankan dan mengembangkan perusahaannya ke arah yang lebih baik.

Tujuan perusahaan pada umumnya adalah memperoleh laba dan memperluas usahanya (ekspansi). Besar kecilnya laba yang dicapai akan menjadi ukuran kesuksesan manajemen dalam mengelola perusahaannya. Kegiatan ekspansi dilakukan dengan penambahan jumlah aktiva tetap yang dimiliki oleh perusahaan.Oleh karena itu, manajemen harus mampu merencanakan dan sekaligus mencapai laba yang besar agar dapat dikatakan sebagai manajemen yang sukses dan mampu mengembangkan bisnis perusahaan di lingkungan industrinya.

Pada umumnya setiap rencana dalam kegiatan usaha selalu bertitik tolak dari investasi. Kegiatan investasi yang dilakukan pada suatu usaha tidak selalu menguntungkan akan tetapi ada juga yang merugikan, hal ini sangat tergantung pada cara pengelolaan dari investasi tersebut yang disesuaikan dengan barang yang akan dijual kepada konsumen. Yaitu berupa pengelolaan modal sendiri atau modal dari luar (asing).Dengan demikian keputusan mengenai investasi memerlukan rencana yang teliti, karena apabila terjadi kesalahan atau kekeliruan dalam pengambilan keputusan investasi, kesalahan itu tidak dapat diperbaiki dalam jangka waktu yang relatif pendek, kesalahan tersebut menyangkut waktu yang panjang, dan menyangkut pula jumlah dana yang besar karenanya kegagalan investasi bukan saja berarti terbuangnya modal secara sia-sia tetapi juga waktu, serta jerih payah, dan bahkan mungkin kehilangan teknologi.

Usaha Mikro Kecil Menengah (UMKM) merupakan industri rumah tangga yang memberikan kontribusi yang cukup signifikan bagi perkembangan ekonomi masyarakat di Kabupaten Lombok Barat, Provinsi Nusa Tenggara Barat (NTB).Pengusaha UMKM pada umumnya masih menggunakan peralatan tradisional dalam proses produksinya. Namun, dengan semakin berkembangnya teknologi maka mereka mulai beralih menggunakan teknologi modern berupa mesin-mesin yang mendukung kegiatan produksinya.

UD.Warna Sari sebagai salah satu unit UMKM yang berada di Desa Suranadi Kecamatan Narmada Kabupaten Lombok Barat telah menjadi unit UMKM yang pertama kali menggunakan mesin-mesin modern untuk mendukung kegiatan produksinya.Mesin-mesin tersebut yaitu oven dan vacuum frying.Mesin-mesin ini sangat bermanfaat untuk mendukung kegiatan produksi dalam skala besar.

UD.Warna Sari terletak di Desa Suranadi Kecamatan Narmada Kabupaten Lombok Barat Provinsi Nusa Tenggara Barat (NTB).Perusahaan industri rumahan ini didirikan pada tahun 1998 oleh keluarga Bapak Mesir Suryadi.Produk utama yang dihasilkannya adalah dodol nangka. Selanjutnya pada tahun 2002 unit UMKM ini memperoleh pembinaan dari Pemerintah Kabupaten Lombok Barat berupa pelatihan teknik pengemasan produk yang akan dijual ke pasar supaya memiliki nilai tambah ekonomi dan kreativitas. Pada tahun 2006 Pemerintah Kabupaten Lombok Barat kembali memberikan pelatihan kepada unit UMKM ini untuk mengembangkan produk baru, yaitu keripik nangka.Barulah pada tahun 2012, Bapak Mesir Suryadi memutuskan mulai menggunakan mesin-mesin modern untuk mendukung kegiatan produksinya, yaitu oven dan vacuum frying.

Pada tahun 2019 ini, Bapak Mesir Suryadi merencanakan untuk menambah kapasitas produksinya. Penjualan yang sangat tinggi akan produknya yaitu dodol nangka menyebabkan beliau mempertimbangkan untuk menambah lagi 1 (satu) unit mesin oven guna mendukung penambahan kapasitas produksinya.Di bawah ini ditampilkan data penjualan dodol nangka yang diproduksi oleh UD. Warna Sari selama tahun 2014-2018 sebagai berikut :

Tabel 1. Penjualan Dodol Nangka Oleh UD. Warna Sari Selama Tahun 2014-2018

\begin{tabular}{|c|c|c|}
\hline Tahun & Penjualan (Rp) & Perubahan (\%) \\
\hline 2014 & 240.000 .000 & - \\
\hline 2015 & 252.000 .000 & 5,00 \\
\hline 2016 & 264.000 .000 & 4,76 \\
\hline 2017 & 276.000 .000 & 4,55 \\
\hline 2018 & 288.000 .000 & 4,35 \\
\hline Jumlah & 1.320 .000 .000 & 18,66 \\
\hline Rata-rata & 264.000 .000 & 4,67 \\
\hline
\end{tabular}

Sumber : UD. Warna Sari, 2019 (diolah).

Dari Tabel $1 \mathrm{di}$ atas terlihat bahwa penjualan dodol nangka oleh Perusahaan UD. Warna Sari terus mengalami peningkatan selama tahun 2014 sampai dengan tahun 2018 dengan rata-rata penjualan sebesar Rp 264.000.000,-. Tetapi, secara persentase (\%) peningkatan mengalami penurunan dari tahun ke tahun dengan 
rata-rata sebesar 4,67 persen.Karena penjualan dodol nangka ini terus mengalami peningkatan maka pada tahun 2019 ini, UD.Warna Sari memutuskan untuk melakukan penambahan aktiva tetap, yaitu 1 (satu) unit mesin oven untuk meningkatkan kapasitas produksinya.

Mesin oven yang baru yang akan dibeli oleh UD. Warna Sari seluruhnya dibiayai dengan modal sendiri. Harga 1 (satu) unit mesin oven ini adalah sebesar Rp 8.000.000,-. Mesin oven ini terdiri dari 2 (dua) sisi, yaitu sisi kanan dan kiri yang masing-masing memiliki 4 (empat) rak yang tersusun dari atas ke bawah.Komponen mesin oven yang digunakan untuk pemanggangan adalah kompor gas yang posisinya tepat berada di tengah-tengah. Apapun kondisi cuaca tidak akan mengganggu aktivitas produksi dodol nangka karena semua proses pengeringannya dilakukan menggunakan mesin oven ini.

\section{Perumusan Masalah}

Berdasarkan uraian latar belakang di atas, maka dapat dirumuskan permasalahan dalam penelitian ini adalah sebagai berikut :

"Apakah rencana investasi penambahan aktiva tetap (mesin oven) tersebut layak dilaksanakan atau tidak oleh UD. Warna Sari, bila ditinjau dari aspek keuangan".

\section{Tujuan Penelitian}

Tujuan penelitian ini adalah untuk menganalisis layak atau tidaknya rencana investasi penambahan aktiva tetap (mesin oven)oleh UD. Warna Sari, bila ditinjau dari aspek keuangan.

\section{METODE PENELITIAN}

Penelitian ini adalah penelitian terapan (applied research). "Penelitian terapan adalah penelitian yang mempunyai alasan praktis, keinginan untuk mengetahui dengan tujuan agar dapat melakukan sesuatu yang jauh lebih baik, lebih efektif dan efisien" (Siregar, 2013:4).Penelitian ini ingin menganalisis layak atau tidaknyarencana investasi penambahan aktiva tetap (mesin oven)oleh UD. Warna Sari, bila ditinjau dari aspek keuangan. Metode pengumpulan data yang digunakan dalam penelitian ini adalah metode kasus atau sering disebut studi kasus (case study). Menurut Maxfield (1930) dalam Nazir (2011:57) menyatakan bahwa "studi kasus (case study) adalah penelitian tentang status subjek penelitian yang berkenan dengan suatu fase spesifik atau khas dari keseluruhan personalitas".Dalam penelitian ini penulis menggunakan studi kasus karena penelitian ini bertujuan untuk meneliti atau menelaah tentang kasus atau kejadian tertentu yang dihadapi olehUD. Warna Sari dalam pengambilan keputusan terkaitrencana investasi penambahan aktiva tetap (mesin oven) yang akan dilaksanakannyabila ditinjau dari aspek keuangan. Adapun teknik pengumpulan data yang digunakan dalam penelitian ini adalah observasi, wawancara, dan dokumentasi yaitu suatu teknik pengumpulan data dari bukti-bukti tertulis, seperti nilai penjualan dan biaya operasional.Alat pengumpulan data yang digunakan dalam penelitian ini adalah kuesioner dan tape recorder.Jenis data yang digunakan dalam penelitian ini adalah data kuantitatif dan data kualitatif.Adapun sumber data yang dipergunakan dalam penelitian ini adalah data primer dan data sekunder.Variabel-variabel yang terkait dalam penelitian ini dapat diidentifikasikan sebagai berikut : 1).Penjualan, 2).Initial investment/original investment 3).Required rate of return, 4). Biaya operasional, 5). Depresiasi, 6). Pajak , 7). Laba bersih (earning after tax), 8). Cashflow. Data yang terkumpul dianalisis dengan : 1). Payback Period (PP), 2). Net Present Value $(N P V), 3)$. Internal Rate of Return (IRR), 4). Profitability Index (PI)

\section{HASIL DAN PEMBAHASAN}

Pada tahun 2019, UD.Warna Sari merencanakan keputusan investasi penambahan aktiva tetap berupa 1 (satu) unit mesin oven. Harga mesin oven ini adalah Rp 8.000.000,- dan memiliki umur ekonomis selama 5 (lima) tahun serta ditaksir memiliki nilai residu sebesar Rp 4.000.000,- pada akhir tahun kelima. Bapak Mesir Suryadi selaku pemilik dan pimpinan pada UD.Warna Sari menetapkan penyusutan untuk seluruh aktiva tetapnya menggunakan metode garis lurus (straight line). Perhitungan penyusutan mesin oven ini adalah sebagai berikut :

Penyusutan per tahun $=(\operatorname{Rp} 8.000 .000-\operatorname{Rp} 4.000 .000): 5=\operatorname{Rp} 800.000,-$ 
Jadi biaya penyusutan untuk mesin oven yang harus dikeluarkan oleh UD. Warna Sari per tahunnya adalah sebesar Rp 800.000,-.

Aliran kas (cashflow) yang berhubungan dengan keputusan investasi penambahan aktiva tetap (mesin oven) yang akan dilaksanakan oleh UD. Warna Sari bisa dikelompokkan dalam 3 (tiga) macam, yaitu :

1. Initial cashflow (nilai investasi awal mesin oven)

2. Operational cashflow (aliran kas yang diperoleh selama umur ekonomis dari mesin oven)

3. Terminal cashflow (nilai residu dari mesin oven pada akhir umur ekonomis).

Biaya penyusutan mesin oven yang dikeluarkan oleh UD. Warna Sari per tahunnya yaitu sebesar Rp 800.000,- sesungguhnya merupakan biaya yang tidak pernah dikeluarkan pada periodenya. Hal ini disebabkan karena biaya penyusutan merupakan pengeluaran tidak tunai.Jika mesin oven tersebut tidak mengalami perbaikan selama umur ekonomis berarti alokasi uang untuk keperluan tersebut dikembalikan ke dalam kas perusahaan.Oleh karena itu, untuk menghitung aliran kas atau cashflow adalah dengan menambahkan laba bersih setelah pajak dengan penyusutan (pengeluaran tidak tunai).Aliran kas (cashflow) yang diperoleh UD. Warna Sari selama umur ekonomis dari keputusan investasi penambahan aktiva tetap (mesin oven) adalah sebagai berikut :

Tabel 2. Perhitungan Aliran Kas (Cashflow) UD. Warna Sari (dalam Rp)

\begin{tabular}{|l|r|r|r|r|r|}
\hline \multicolumn{1}{|c|}{ KETERANGAN } & \multicolumn{1}{c|}{ Tahun 1 } & \multicolumn{1}{c|}{ Tahun 2 } & \multicolumn{1}{c|}{ Tahun 3 } & \multicolumn{1}{c|}{ Tahun 4 } & \multicolumn{1}{c|}{ Tahun 5 } \\
\hline PENJUALAN & 240.000 .000 & 252.000 .000 & 264.000 .000 & 276.000 .000 & 288.000 .000 \\
\hline Biaya Variabel & 1.800 .000 & 1.800 .000 & 1.800 .000 & 1.800 .000 & 1.800 .000 \\
\hline Biaya Tetap Non Penyusutan & 15.840 .000 & 15.840 .000 & 15.840 .000 & 15.840 .000 & 15.840 .000 \\
\hline Biaya Tetap Penyusutan & 800.000 & 800.000 & 800.000 & 800.000 & 800.000 \\
\hline TOTAL BIAYA & 18.440 .000 & 18.440 .000 & 18.440 .000 & 18.440 .000 & 18.440 .000 \\
\hline EARNING BEFORE TAX $(E B T)$ & 221.560 .000 & 233.560 .000 & 245.560 .000 & 257.560 .000 & 269.560 .000 \\
\hline PAJAK 1\% & 2.215 .600 & 2.335 .600 & 2.455 .600 & 2.575 .600 & 2.695 .600 \\
\hline EARNING AFTER TAX $(E A T)$ & 219.344 .400 & 231.224 .400 & 243.104 .400 & 254.984 .400 & 266.864 .400 \\
\hline Penyusutan & 800.000 & 800.000 & 800.000 & 800.000 & 800.000 \\
\hline Nilai Residu & - & - & - & & - \\
\hline Cashflow & 220.144 .400 & 232.024 .400 & 243.904 .400 & 255.784 .400 & 271.664 .400 \\
\hline
\end{tabular}

Sumber : Data primer diolah

Tingkat pengembalian yang disyaratkan (Required Rate of Return/RRR) oleh UD.Warna Sari dalam keputusan investasi penambahan aktiva tetap (mesin oven) adalah sebesar 40\%.Perhitungan penilaian kelayakan keputusan investasi penambahan aktiva tetap (mesin oven) oleh UD. Warna Sari dengan menggunakan metode Net Present Value (NPV) dengan $R R R=40 \%$ adalah sebagai berikut :

Tabel 3. Perhitungan Net Present Value (NPV) Mesin Oven (dalam Rp)

\begin{tabular}{|l|c|c|c|}
\hline TAHUN & CASHFLOW & $\begin{array}{l}\text { DISCOUNT FACTOR } \\
\mathbf{R}=\mathbf{4 0 \%}\end{array}$ & $\begin{array}{l}\text { PRESENT VALUE } \\
\text { OF CASHFLOW }\end{array}$ \\
\hline 1 & 220.144 .400 & 0,714 & 157.183 .102 \\
\hline 2 & 232.024 .400 & 0,510 & 118.332 .444 \\
\hline 3 & 243.904 .400 & 0,364 & 88.781 .202 \\
\hline 4 & 255.784 .400 & 0,260 & 66.503 .944 \\
\hline 5 & 271.664 .400 & 0,186 & 50.529 .578 \\
\hline \multicolumn{2}{|l|}{ Total Present Value of Cashflow } & 481.330 .270 \\
\hline \multicolumn{2}{|l|}{ Present Value of Investment } & 8.000 .000 \\
\hline \multicolumn{2}{|l|}{ NET PRESENT VALUE } & 473.330 .270 \\
\hline
\end{tabular}

Sumber : Data primer diolah

Dengan menggunakan tingkat pengembalian yang disyaratkan (Required Rate of Return/RRR) sebesar 40\%, ternyata diperoleh hasil Net Present Value (NPV) sebesar Rp 473.330.270,-. Artinya dengan NPV 
positif sebesar Rp 473.330.270,- maka keputusan investasi penambahan aktiva tetap (mesin oven) oleh UD. Warna Sari ini layak untuk dilaksanakan.

Selanjutnya menggunakan hasil perhitungan $N P V$ di atas, yang telah ditemukan $N P V$ yang bernilai positif sebesarRp 473.330.270,- dengan $R R R$ sebesar $40 \%$ maka dicari $N P V$ yang bernilai negatif dengan menaikkan tingkat $R R R$ menjadi sebesar 50\%. Hasil perhitungan $N P V$ dengan $R R R$ sebesar 50\%, diperoleh $N P V$ sebesar Rp 400.555.863,-. Dengan demikian Internal Rate of Return (IRR) bisa kita hitung dengan membuat interpolasi sebagai berikut :

$$
I R R=40 \%+\frac{473.330 .270}{481.330 .270-408.555 .863} \times(50 \%-40 \%)=105,04 \%
$$

Karena Internal Rate of Return (IRR) yang diperoleh sebesar 105,04\% lebih besar dari tingkat pengembalian yang disyaratkan (Required Rate of Return/RRR) oleh UD. Warna Sari maka keputusan investasi penambahan aktiva tetap (mesin oven) ini layak untuk dilaksanakan.

UD.Warna Sari mensyaratkan bahwa periode pembayaran kembali maksimum 1 tahun untuk keputusan investasi penambahan aktiva tetap (mesin oven). Dengan demikian, perhitungan periode pembayaran kembali (Payback Period/PP) adalah sebagai berikut :

Tabel 4.Cashflow dan Kumulatif Cashflow Mesin Oven(dalam Rp)

\begin{tabular}{|l|l|l|}
\hline TAHUN & CASHFLOW & KUMULATIF CASHFLOW \\
\hline 1 & 220.144 .400 & 220.144 .400 \\
\hline 2 & 232.024 .400 & 452.168 .800 \\
\hline 3 & 243.904 .400 & 696.073 .200 \\
\hline 4 & 255.784 .400 & 951.857 .600 \\
\hline 5 & 271.664 .400 & 1.223 .522 .000 \\
\hline
\end{tabular}

$P P=1+\frac{8.000 .000-220.144 .400}{452.168 .800-220.144 .400} \times 1$ tahun $=0,09$ tahun

Angka periode pembayaran kembali (Payback Period/PP) sebanyak 0,09 tahun, artinya bahwa jangka waktu yang diperlukan untuk mengembalikan nilai keputusan investasi penambahan aktiva tetap (mesin oven) senilai $\mathrm{Rp} 8.000 .000$,- adalah 0,09 tahun ( 0 tahun 0 bulan 9 minggu).Jika UD. Warna Sari mensyaratkan bahwa periode pembayaran kembali maksimum 1 tahun maka keputusan investasi ini layak dilaksanakan.

Profitability Index $(P I)$ merupakan metode yang akan memberikan hasil yang konsisten dengan metode $N P V$. Perhitungan Profitability Index (PI) untuk keputusan investasi penambahan aktiva tetap (mesin oven) oleh UD. Warna Sari adalah sebagai berikut :

$$
P I=\frac{481 \cdot 330 \cdot 270}{8.000 .000}=60,17
$$

Dengan demikian, karena keputusan investasi penambahan aktiva tetap (mesin oven) oleh UD. Warna Sari menghasilkan $P I$ sebesar 60,17 yang berarti lebih besar dari 1 maka keputusan investasi ini layak untuk dilaksanakan.

\section{SIMPULAN DAN SARAN}

\section{Simpulan}

Dari hasil penelitian ini dapat disimpulkan sebagai berikut :

Rencana investasi penambahan aktiva tetap (mesin oven) tersebut layak dilaksanakan oleh UD. Warna Sari, bila ditinjau dari aspek keuangan. Hal ini dapat dlihat dari Payback Period $(P P)=0,09$ tahun $<1$ tahun, Net Present Value (NPV) sebesar Rp 473.330.270 bernilai positif, IRR $(105,04 \%)>$ RRR $(50 \%)$, PI $(60,17)>1$ 


\section{Saran}

Bagi pimpinan UD. Warna Sari, keputusan investasi penambahan aktiva tetap (mesin oven) ini layak untuk dilaksanakan untuk meningkatkan kapasitas produksi dodol nangka yang nilai penjualanya terus mengalami peningkatan dari tahun ke tahun.

\section{DAFTAR PUSTAKA}

Chairudin, Teguh. 1996. Analisis Tingkat Pengembalian Investasi Aktiva Tetap (Kapal) pada PT. Penyeberangan Munawar Lintas Pelabuhan Kayangan - Pototano. Fakultas Ekonomi Universitas Mataram : Skripsi tidak dipublikasikan.

Dunia, Firdaus A. 2013. Pengantar Akuntansi. Edisi Keempat. Lembaga Penerbit Fakultas Ekonomi Universitas Indonesia : Jakarta.

Hadibroto. 2006. Dasar-dasar Akuntansi. LP3ES : Jakarta.

Halim, Abdul. 2015. Analisis Investasi dan Aplikasinya : Dalam Aset Keuangan dan Aset Riil. Salemba Empat : Jakarta.

Jusup, Al. Haryono. 2005. Dasar-dasar Akuntansi. Jilid 2.Edisi ke-6. Sekolah Tinggi Ilmu Ekonomi YKPN : Yogyakarta.

Nazir, Moh. 2011. Metode Penelitian. Cetakan Ketujuh. Ghalia Indonesia : Bogor.

Nurraehan.1990. Analisa Investasi Penambahan Mesin Baru pada Perusahaan Penggilingan Padi UD.Semeton di Desa Lingsar Lombok Barat. Fakultas Ekonomi Universitas Mataram : Skripsi tidak dipublikasikan.

Siregar, Syofian. 2013. Metode Penelitian Kuantitatif : Dilengkapi dengan Perbandingan Perhitungan Manual dan SPSS. Edisi Pertama. Kencana Predana Media Group , Jakarta.

Sutrisno. 2012. Manajemen Keuangan : Teori, Konsep, dan Aplikasi. Ekonisia, Yogyakarta.

Yudiasti, Ery. 2008. Analisis Kelayakan Investasi pada Usaha Jasa Internet di Kelurahan Dasan Agung Baru Kota Mataram. Fakultas Ekonomi Universitas Mataram : Skripsi tidak dipublikasikan. 